\title{
The new specialty training for future consultants in sexual and reproductive health
}

\author{
Ailsa E Gebbie, Christine Robinson, Gordon Watson
}

\section{Background}

There is widespread acknowledgement that the UK has poor levels of sexual health compared to our immediate European neighbours. The reasons for this are deep seated, complex and not easily amenable to change. One important part of the solution is to raise and sustain a high quality of community-based clinical sexual and reproductive health (SRH) services within the National Health Service (NHS); services which until recently suffered from a low priority and major disinvestment. Sexual health strategies from all four devolved UK nations have supported the concept of strong clinical leadership for multidisciplinary and multiprofessional SRH teams within the NHS in order to achieve targets such as reducing teenage pregnancy, abortion and sexually transmitted infection rates. Leadership of effective specialist SRH services is only possible if clinicians have received an appropriate and 'fit for purpose' training.

The first tranche of consultants appointed in the late 1980s were largely from an obstetrics and gynaecology $(\mathrm{O} \& \mathrm{G})$ background. More recent consultant appointments have been to individuals, who again trained in $\mathrm{O} \& \mathrm{G}$, but who had acquired specific knowledge and skills by undertaking the subspecialty training in sexual and reproductive health of the Royal College of Obstetricians and Gynaecologists (RCOG). All recent workforce census figures have shown a serious shortage of appropriately trained consultants to meet the current vacancies and those likely to arise in the near future. In addition, subspecialty posts in SRH are often unfilled because of a lack of suitable trainees with a genuine commitment to the specialty. As trainees have to complete 5 years of mainstream $O \& G$ with in-depth obstetrics before undertaking subspecialty training, they have often missed the opportunity to be exposed to the challenges and breadth of SRH.

One other significant factor has strongly impacted on the situation. SRH now has a solid core of doctors working in the specialty who have consolidated their specialist knowledge by achieving the Membership examination of the Faculty of Sexual and Reproductive Healthcare (MFSRH). Some will also have undertaken structured Faculty training as career grade trainees. These doctors have great difficulty applying to the Postgraduate Medical Education Training Board (PMETB) for equivalence of training to lead to a Certificate of Completion of Training (CCT) because the current criteria are determined by the core specialty of O\&G. A separate 'fit for purpose' training programme in SRH would pave the way for these clinicians to apply for assessment of equivalence in the new specialty, which would lead to eligibility for a Certificate of

J Fam Plann Reprod Health Care 2010; 36(2): 70-71

NHS Lothian Family Planning/Well Woman Services, Dean Terrace Centre, Edinburgh, UK

Ailsa Gebbie, FRCOG, FFSRH, Consultant Gynaecologist

Faculty of Sexual and Reproductive Healthcare, London, UK Christine Robinson, FRCOG, FFSRH, President; and Consultant Gynaecologist, Southwark Primary Care Trust, London, UK Gordon Watson, BSc, PhD, Educational Adviser

Correspondence to: Dr Ailsa Gebbie, Dean Terrace Centre, 18 Dean Terrace, Edinburgh EH4 1NL, UK.

E-mail: ailsa.gebbie@nhslothian.scot.nhs.uk
Eligibility for Specialist Registration (CESR) and consultant appointment.

\section{Process}

Throughout 2006-2007, representatives from the FSRH and RCOG (the parent college) met with the Department of Health's (DH) Public Health Workforce Capacity lead, representatives from PMETB and the DH's Sexual Health team to explore the issues related to the workforce, training and leadership issues in SRH. Following these discussions, it became clear that the Faculty should pursue a separate CCT with a 'fit for purpose' training programme emphasising the skills required for a consultant career in SRH. The First Stage document presenting the case for the development of a new specialty in SRH was submitted to the DH in January 2008 and was approved in July 2008. This document outlined in detail twelve principles for the case and was thoroughly assessed by all relevant UK stakeholders.

One problem arose at this stage. As SRH already existed as a 'subspecialty', it was not possible to have a 'specialty' with the same name. The matter was put before Faculty Council in early 2009 and members were asked to consider a selection of new titles. The name Community Sexual and Reproductive Health (CSRH) was selected by the majority as being most appropriate for the new specialty.

A larger and more comprehensive Second Stage document was submitted to the DH in February 2009. This included details of the proposed CSRH training programme in terms of the training structure, the curriculum, the portfolio, selection of trainees and assessment methods. Two examplar modules from the curriculum on Basic Clinical Skills and Contraception were included as appendices. The DH commenced a formal consultation on the recognition of CSRH as a separate specialty following a slight delay, because they wished to link the application to that of another prospective specialty allowing stakeholders to be contacted only once with both applications. The stakeholder consultation ended in June 2009 and received approval from the Secretary of State the same month. The application was put before UK Parliament in July and became officially recognised through lay regulations as a separate specialty in August 2009.

The lead Dean, Professor Simon Gregory, and host Deanery for CSRH were appointed in July 2009. The lead Dean will advise on matters relating to quality management of training, and with the Deanery will co-ordinate the recruitment and selection process, Annual Review of Competence Progression (ARCP) assessments of trainees and sign off their CCTs.

\section{Curriculum}

Faculty Council approved the appointment of a lead clinician and educational adviser to work on the project commencing in November 2008. A curriculum group was selected that included present subspecialty trainers, SRH and $O \& G$ consultants, current and recent trainees, lay representation and administrative support. The group held formal all-day meetings to debate rigorously the format of the curriculum, appoint module editors and put together the 


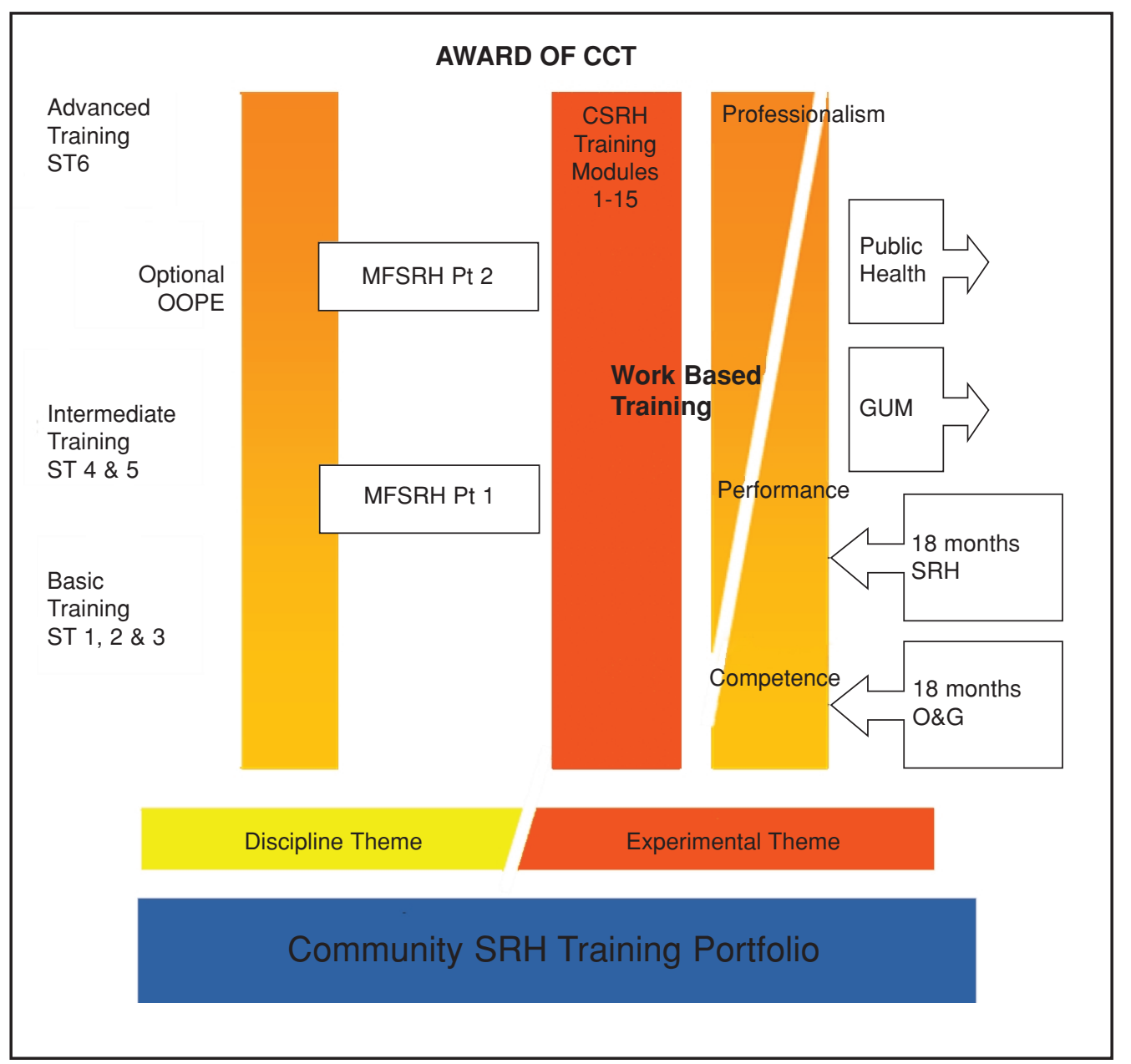

Figure 1 Community Sexual and Reproductive Health (CSRH) training pathway. CCT, Certificate of Completion of Training; GUM, genitourinary medicine; MFSRH, Membership of the Faculty of Sexual and Reproductive Healthcare; O\&G, obstetrics and gynaecology; OOPE, out of programme experience; Pt, Part; $\mathrm{SRH}$, sexual and reproductive health; ST, specialty trainee

whole curriculum. Fifteen modules were developed for the final curriculum (Figure 1). Two editors were appointed for each module which, when completed, was peer reviewed by two other experts in the field. There was lay review and trainee review of all modules. Input was obtained from colleagues working in $O \& G$, genitourinary medicine and public health. The layout and format already adopted by the RCOG was followed, to allow harmonisation of the two curricula, as trainees will follow a common 18 months in $O \& G$ within their basic training.

\section{PMETB}

All medical training curricula have to be approved by PMETB and be shown to comply with a set of comprehensive standards. These standards were recently updated and are challenging in their depth and detail. PMETB was presented with the entire CSRH curriculum and responses to their standards on 11 August 2009. Four representatives from the Faculty met the PMETB panel on 22 September 2009 to discuss the curriculum and respond to queries. In November 2009, PMETB approved the curriculum subject to a short list of conditions. The Faculty responded to these conditions, and in January 2010 PMETB gave unconditional approval of the entire curriculum and assessment system.

\section{The Future}

Running a modern medical specialty is a complex process and is subject to much more scrutiny now than in the past. The curriculum alone has to be constantly updated and reassessed by PMETB. Almost all specialties are moving towards an electronic platform for the trainees' portfolios and considerable resources are required to support the administration of the entire process. The Lead Dean is constituting a Specialty Advisory Committee with a chairperson, which will be responsible for strategic decisions regarding the specialty training programme. Regional Training Programme Directors, Faculty tutors and educational advisers will need to be appointed and training centres will need to be approved by PMETB. A 'Train the Trainers' day on the new specialty has been held and will be repeated annually.

The last - and vital - participants in this process are the trainees themselves. Some centres have offered 'taster weeks' in SRH for foundation trainees, and many young doctors appear interested in a career pathway in SRH. Existing subspecialty trainees will continue in their current posts and it is hoped that these funded posts will subsequently be used for specialty training. Clearly this is inadequate to provide enough trainees to replace the potential consultant vacancies and, with some success to date, strenuous efforts are underway to secure new training posts in the specialty. With devolution of health to separate UK nations, this involves dialogue with each nation's workforce planning team. The current financial recession and cutbacks in training budgets may impact significantly on funding opportunities for new posts.

The move towards specialty training in CSRH marks an exciting challenge for the Faculty. Much progress has already been made; and with sustained effort over the next few years, the SRH consultants of the future are poised to be trained through a 'fit for purpose' specialty training programme.

Statements on funding and competing interests Funding None identified. Competing interests None identified. 